\title{
Iron-rich laterite-bagasse fibers based geopolymer composite: Mechanical, durability and insulating properties
}

\author{
R.Y. Nkwaju ${ }^{a}$, J.N.Y. Djobo ${ }^{a}{ }^{*}$, J.N.F. Nouping ${ }^{a}$, P.W.M. Huisken ${ }^{b}$, J.G.N. Deutou ${ }^{a}$, L. Courard ${ }^{c}$ \\ ${ }^{a}$ Loecal Materials Promotion Authority, MINRESI/MIPROMALO, P.O. Box 2396, Nkolbikok, Yaoundé, Cameroon \\ ${ }^{\mathrm{b}}$ Mechanical Laboratory and Adapted Materials (LAMMA) ENSET, University of Douala, Cameroon \\ ${ }^{\mathrm{c}}$ Department of Architecture, Geology, Environment and Construction, University of Liège, Belgium
}

\section{A R T I C L E I N F O}

Keywords

Bagasse fibers

Fracture behavior

Durability

Insulating properties

Iron-rich laterite

Geopolymer composite

\begin{abstract}
A B S T R A C T
This work reports the mechanical, durability and insulating properties of novel geopolymer composites made of iron-rich laterite and sugarcane bagasse fibers with sodium silicate as a hardener. The results showed that the addition of fibers was beneficial for improving the fracture behavior of iron-rich laterite based geopolymer from brittle to ductile. The 28 days compressive strength ranges from $50 \mathrm{MPa}$ to $14 \mathrm{MPa}$ with the content of fibers. The modulus of elasticity was improved by $50 \%$ with only $3 \mathrm{wt} \%$ of fibers. The geopolymer composites perform well after 20 wet-dry cycles with the improvement of its ductility. The 28 days thermal conductivity decreases from $0.77 \mathrm{~W} / \mathrm{mK}$ to $0.55 \mathrm{~W} / \mathrm{mK}$ with the fibers content.
\end{abstract}

\section{Introduction}

Laterite is a highly weathered aluminosilicate with iron $\left(\mathrm{Fe}^{2+}, \mathrm{Fe}^{3+}\right)$ replacing aluminum $\left(\mathrm{Al}^{3+}\right)$ during laterization process (chemical alteration of clayed minerals and hardening upon exposure to wet and dry condition over time) (Obonyo et al., 2014; Oyelami and Van Rooy, 2016). Iron-rich laterite has been gaining more attention in recent years for developing geopolymer materials. This because of their availability in a tropical area, for example over $67 \%$ of the territory of Cameroon (Oyelami and Van Rooy, 2016). Also, the presence of iron which modifies the chemistry of the resulting system compared to other aluminosilicate based geopolymer makes iron-rich laterite-based geopolymer interesting for further studies. The change of the chemistry includes the iron incorporation in the 3D network playing the same role like $\mathrm{Al}$ (Lemougna et al., 2013; Djobo et al., 2016a, 2016b; Kaze et al., 2017; Kaze et al., 2018b). Moreover, physical and mechanical properties of the iron-rich laterite based geopolymer were reported to be good enough to allow their use as construction materials (Lemougna et al., 2014; Lassinantti Gualtieri et al., 2015; Kaze et al., 2017, 2018a, 2018 b). However, they exhibit brittle failure like most of the other aluminosilicate-based geopolymer materials, which limits some of its applications in industry.

Research works have been carried out for altering brittle failure of cement based-materials into ductile failure (Silva et al., 2009; Alomayri et al., 2013; Shaikh, 2013; Bhutta et al., 2017; Ye et al., 2018; Sikora et al., 2019). This includes the use of synthetic and natural fibers as reinforcements. Compared to synthetic fibers, natural fibers are beneficial since they are widely available, cost-effective, renewable, and their exploitation is environmental friendly (Assaedi et al., 2018). A recent review reported the use of natural fibers as reinforcement materials in the cementitious matrix and the engineering properties of the resulting composites (Yan et al., 2016). It was shown that for instance only cellulose (Ye et al., 2018), flax fabric (Assaedi et al., 2015), cotton fibers (Alomayri et al., 2013, 2014b), and luffa cylindrical (Alshaaer et al., 2017) have been used as natural fibers for the reinforcement of the geopolymer matrix. These works highlighted the improvement of the physical and mechanical properties of composites. However, there is a lack of data regarding the durability properties of natural fibers reinforced geopolymer composite. The thermal and electrical conductivity properties of metakaolin based-geopolymer has recently been reported (Sellami et al., 2019). But, the insulating properties of geopolymer from iron-rich laterite has not yet been reported in the literature as well as the characteristic of its composite.

Thus, this work aims at synthesizing and reporting the mechanical, durability and insulating characteristics of a geopolymer composite from iron-rich laterite and bagasse fibers with sodium silicate as a hardener. The raw materials and the geopolymer binder were characterized for understanding their specific characteristics. These were done by determining their physical, chemical and microstructural properties using X-ray Fluorescence, X-ray Diffractometry, Fourier Transformed Infra-red spectroscopy and Scanning Electron Microscopy coupled

\footnotetext{
* Corresponding author.

E-mail address: noeldjobo@gmail.com (J.N.Y. Djobo)
} 
with -Energy Dispersive X-ray spectroscopy. The effectiveness of bagasse fiber for improving the ductility was assessed by measuring the strain behavior under compression and flexural stress. The SEM was used to highlight the microstructure of the bagasse fibers and explain the failure mechanism of the composite. The durability was investigated by determining water absorption rate, and the fracture behavior of geopolymer composite after 20 wet-dry cycles. The insulating properties were assessed by measuring the thermal conductivity of geopolymer at different ages.

\section{Experimental methods}

\subsection{Materials}

The lateritic soil used in this study was collected at Emana-Yaounde in the center region of Cameroon. The material was ground up to total particles passing through a $200 \mu \mathrm{m}$ mesh sieve. Laterite was calcined at $700{ }^{\circ} \mathrm{C}$ for $4 \mathrm{~h}$ at a heating rate of $5^{\circ} \mathrm{C} / \mathrm{min}$ in a programmable electric furnace. The chemical composition of the raw laterite determined by X-ray fluorescence spectrometer Bruker S8 Tiger is reported in Table 1. The particle size distribution recorded using a laser particle size analyzer (MASTERSIZER 2000 Ver 5.60, Malvern, UK) is shown in Fig. 1. The mean diameters are $64.4 \mu \mathrm{m}$ and $46.8 \mu \mathrm{m}$ for raw and calcined laterite respectively.

Sugarcane bagasse fibers (SCBF) used are industrial by-products from local sugar producing company (SOSUCAM) in Cameroon situated at Mbandjock in the center region. The length of as-received fibers varies from 2 to $10 \mathrm{~cm}$. They were dried under the ambient condition to reduce their moisture content. No more treatment was applied to the fibers.

The alkaline solution used as an activator was prepared by dissolving $9 \mathrm{M}$ solution of sodium hydroxide ( $\mathrm{NaOH}, 99.99 \%$, Sigma-Aldrich) with sodium silicate solution in order to have a solution with a molar ratio of $\mathrm{SiO}_{2} / \mathrm{Na}_{2} \mathrm{O}=1.4$. The alkaline solutions were sealed and stored for a minimum of $24 \mathrm{~h}$ prior to use.

\subsection{Preparation of geopolymer composite}

For the preparation of geopolymer composites, the different mass percentage of SCBF calculated versus the mass of calcined powder laterite were considered: $0,1.5,3,4.5,6$ and $7.5 \mathrm{wt} \%$ respectively. These ratios correspond to $0,1.73,3.47,5.21,6.94$ and $8.68 \% \mathrm{~V} / \mathrm{V}$ of the total volume of each specimen. The liquid/ calcined laterite mass ratio was maintained at 0.6 for all the mixtures. Alkaline solution was added to each calcined powder laterite and mixed for $5 \mathrm{~min}$. Then, the SCBF fibers were added to the paste and further mixed for $5 \mathrm{~min}$. It must be stressed that the fibers were used as received so they have random geometry and length. At this stage, the idea is to first investigate how the random orientation and length of the fibers within the matrix affect the final properties of the geopolymer composite. The composite pastes obtained were cast in 40x40x160 mm prismatic mold and covered with a plastic bag to avoid rapid water evaporation. The samples were cured at room temperature for $24 \mathrm{~h}$ before demolding and stored again into a plastic bag at the laboratory temperature $\left(20 \pm 2{ }^{\circ} \mathrm{C}\right)$ until performing tests.

\subsection{Analytical techniques}

The mineralogical composition and the mineral content were determined on fine powder of metakaolin and geopolymer samples by using Bruker X-ray diffractometer (D8 Advance, US) with $\mathrm{Cu} \mathrm{K} \alpha 1$ radiation $(\mathrm{WL}=1.54 \AA$ ), at $35 \mathrm{kV}, 45 \mathrm{~mA}$. The $\mathrm{XRD}$ patterns were recorded in the range of $3-63^{\circ} 2 \theta$. High score plus software was used to identify all minerals present and quantify their relative content excluding the amorphous phase by applying the Rietveld method.

The IR spectra were recorded using a Bruker IFS 55 spectrometer equipped with an MCT detector. The analysis was performed on $\mathrm{KBr}$ pellets containing $15 \%$ of the activated sample (LA, LAC, GEO). For each sample, 50 scans with a resolution of $4 \mathrm{~cm}^{-1}$ were recorded in the frequency range $4000-400 \mathrm{~cm}^{-1}$.

The Scanning Electron Microscope equipped with energy-dispersive X-ray device (SEM-EDX, Bruker (US)) was used for the analysis of the microstructure and the phase composition of the geopolymer binder. The geopolymer samples were first gold coated and dried before putting into Microscope operated at $15.0 \mathrm{kV}$. This analysis was also used to observe the failure mechanism of the geopolymer composite.

The flexural strength of the geopolymer was measured at 28 days aged 40x40x160 mm and the two broken pieces were used for compressive strength measurement. The tests were performed on three samples according to EN 196-1, and the average was taken as the final value.

Sorptivity test was used to measure the rate of water penetration by capillary suction into the geopolymer matrix. The test was performed according to ASTM C 642-82. The cubic samples of 40x40x40 mm were oven-dried for $24 \mathrm{~h}$ and then cooled for $24 \mathrm{~h}$. The lateral sides of the samples were sealed using an impermeable tape. The initial mass of the sample was measured and immersed up to a depth of 5-10 $\mathrm{mm}$ in water; the mass was measured at different time intervals.

The resistance of the geopolymer composite to wet and dry cycle was assessed by measuring the strength and mass change of samples after $0,5,10$ and 20 cycles. One cycle consists of drying the specimens at $60^{\circ} \mathrm{C}$ for $24 \mathrm{~h}$ followed by immersion into water for another $24 \mathrm{~h}$. This test procedure was carried out as described in previous works (Mohr et al., 2005; Djobo et al., 2016b).The thermal conductivity test was performed at different ages up to 28 days. This test is carried out on a cylindrical sample of Geopolymer of the $150 \times 50 \mathrm{~mm}$. one applies one heat source known in the center the sample, one measures thermal conductivity transmitted by the sample using thermocouple present in the probe. It is in accordance with ASTM D5334-00 \& D5930-97.

\section{Results and discussion}

\subsection{Mineralogical and microstructural characteristics of laterite and geopolymer binder}

\subsubsection{Mineralogical characteristics}

The X-ray patterns of raw, calcined laterite and neat geopolymer are depicted in Fig. 2, and the results of the quantitative phase analysis are reported in Table 2. The raw laterite is constituted of Kaolinite (34 wt $\%)$, Goethite (29wt\%) and Quartz (25wt\%) as main minerals. Hematite ( $8 w t \%)$, Gibbsite ( $2 w t \%)$, Anatase (1wt\%) and Illite (2wt $\%)$ are the secondary phases. After calcination, only Hematite, Quartz,

Table 1

Chemical composition of raw laterite.

\begin{tabular}{|c|c|c|c|c|c|c|c|c|c|c|c|}
\hline Oxide & $\mathrm{SiO}_{2}$ & $\mathrm{Al}_{2} \mathrm{O}_{3}$ & $\mathrm{Fe}_{2} \mathrm{O}_{3}$ & $\mathrm{TiO}_{2}$ & $\mathrm{MnO}$ & $\mathrm{MgO}$ & $\mathrm{CaO}$ & $\mathrm{K}_{2} \mathrm{O}$ & $\mathrm{P}_{2} \mathrm{O}_{5}$ & LOI & Total \\
\hline $\mathrm{Wt} \%$ & 33.18 & 17.89 & 35.33 & 1.08 & 0.56 & 0.23 & 0.09 & 0.05 & 0.34 & 11.84 & 100.59 \\
\hline
\end{tabular}



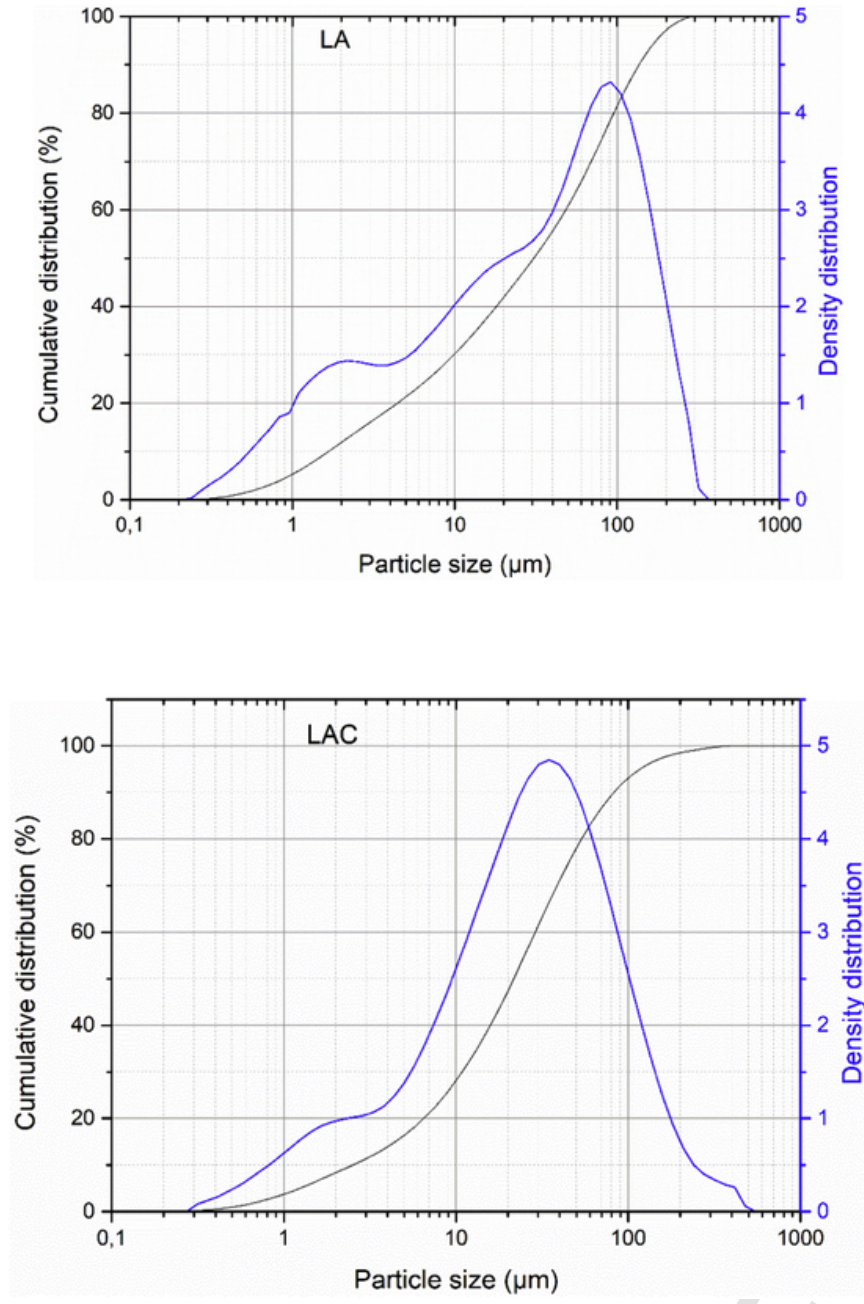

Fig. 1. Particle size distribution of raw (LA) and calcined laterite (LAC).

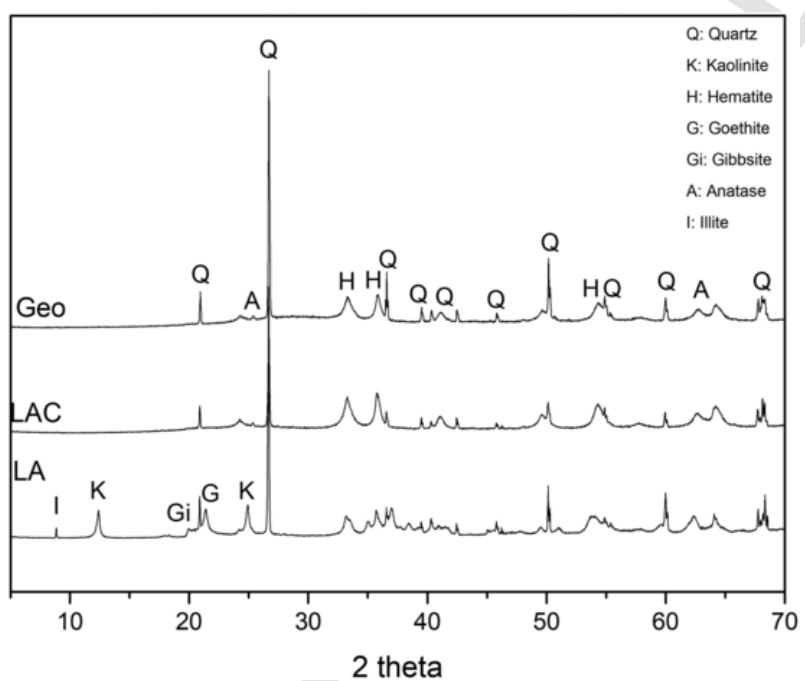

Fig. 2. X-ray patterns of raw (LA), calcined laterite (LAC) and neat Geopolymer (Geo).

and Anatase remain as main minerals phases with a content up to 70 , 27 and $3 \mathrm{wt} \%$ respectively. The higher content of the hematite is due to the dehydroxylation of goethite into the most stable iron oxide $\mathrm{Fe}_{2} \mathrm{O}_{3}$ during calcination (Kaze et al., 2017). After geopolymerization, it is observed an increase of the Quartz content to $38 \mathrm{wt} \%$ in parallel to the decrease in the amount of Hematite and Anatase. The decrease of the relative amount of hematite in geopolymer sample might indicate that it has partially reacted (Djobo et al., 2016a; Kaze et al., 2018a). The increase of the relative amount of quartz translates the fact that the latter remains inert in the matrix and does not take part in the geopolymerization.

The IR spectrum of the raw laterite is characterized by the band at $3699-3619 \mathrm{~cm}^{-1}$ and $1631 \mathrm{~cm}^{-1}$ translating respectively the $\mathrm{O}-\mathrm{H}$ stretching and bending vibration bond linked to $\mathrm{Al}$ in the structure of kaolinite; moreover, the band at $3453 \mathrm{~cm}^{-1}$ corresponds to $\mathrm{O}-\mathrm{H}$ stretching vibration bond linked to Fe atoms in the structure of goethite (Kaze et al., 2017). After calcination, these bands have disappeared and one observed at 3434 and $1641 \mathrm{~cm}^{-1}$ are related to the stretching and bending vibration of $\mathrm{O}-\mathrm{H}$ bonds from the residual water molecules contained in the amorphous phase of silanol $\left(\mathrm{Si}(\mathrm{OH})_{4}\right.$ ) (Gouny et al., 2014). The same type of bands observed in the geopolymer cement is also related to the water contained into the geopolymer network; It is indeed well known that a part of water initially presents either in the aluminosilicate or sodium silicate that take part to geopolymerization (Zuhua et al., 2009). The weak band appearing at $1383 \mathrm{~cm}^{-1}$ only on the spectrum of geopolymer specimen corresponds to the vibration of the $\mathrm{C}-\mathrm{O}$ bonds of the carbonate groups that come from the reaction of the unreacted sodium contained in the pore solution with the $\mathrm{CO}_{2}$ of the air: it characterizes the efflorescence (Najafi Kani et al., 2012). However, the very low intensity of that band means that the efflorescence extent is very low in this system. It consequently means that the proportion of $\mathrm{Al}$ and $\mathrm{Fe}$ atoms that reacted from laterite was high enough to allow an equilibrated stoichiometry of $\mathrm{Na} / \mathrm{Al}$ and $\mathrm{Na} / \mathrm{Fe}$ and limited the availability of free $\mathrm{Na}^{+}$in the matrix. The bands between 913 and $113 \mathrm{~cm}^{-1}$ on raw laterite, which are characteristic of symmetric vibration of $\mathrm{Si}-\mathrm{O}-\mathrm{T}$ bonds $(\mathrm{T}=\mathrm{Si}, \mathrm{Al}, \mathrm{Fe}$ ), have disappeared after calcination to give rise to a broad band centered at $1085 \mathrm{~cm}^{-1}$. There is also the band at $692 \mathrm{~cm}^{-1}$ related to the bending vibration of $\mathrm{Fe}-\mathrm{OH}$ bond of goethite which disappears after calcination. These translate the dehydroxylation of hydrated minerals (kaolinite, Goethite, gibbsite, and Illite) reported in XRD results (Kaze et al., 2017, 2018b). Moreover, that band $\left(1085 \mathrm{~cm}^{-1}\right)$ has shifted toward low value after geopolymerization because of the structural change due to the replacement of $\mathrm{Si}$ atoms by $\mathrm{Al}$ and $\mathrm{Fe}$ in the silicate chain inducing the diminishing of its length. Finally, the band at $450-550 \mathrm{~cm}^{-1}$ is related to the $\mathrm{Fe}-\mathrm{O}$ stretching vibration bond in iron phases (goethite and hematite).

\subsubsection{Microstructure}

The micrograph and the mapping of the distribution of elements throughout the matrix of geopolymer are shown in Fig. 4. The geopolymer has a dense microstructure with very few cracks. The elemental map shows a heterogeneous distribution of the main elements $\mathrm{Si}$ and Fe which are both characterized by bright and non-bright features; on the contrary, $\mathrm{Al}$ and $\mathrm{Na}$ are homogenously distributed throughout the matrix and only display a non-bright feature. The combined elementary mapping and the EDX results (Table 3 ) helped to identify unreacted particles of quartz, hematite, and metakaolin as well as geopolymer binder. The unreacted metakaolin particles are identified on combined elemental map by the bright feature with color like the one of $\mathrm{Al}$ map. The others bright features correspond to quartz and hematite, whereas the non-bright features correspond to geopolymer binder and unreacted particles (metakaolin, quartz, and hematite) covered by the geopolymer binder. On Table 3 it can be observed that two types of geopolymer binder were obtained: the first one with the chemical composition in a molar ratio of $\mathrm{Si} / \mathrm{Al}=1.55-1.63, \mathrm{Si}$ / $\mathrm{Fe}=3.45-6.07, \mathrm{Na} / \mathrm{Al}=0.98-1.1, \mathrm{Na} / \mathrm{Fe}=1.96-3.49$ belongs to polyferrosialate siloxo binder type. The second one is composed of 
Table 2

Relative mineral content by quantitative XRD.

\begin{tabular}{|c|c|c|c|c|c|c|c|}
\hline Mineral content & Quartz & Kaolinite & Anatase & Illite & Goethite & Hematite & Gibbsite \\
\hline Laterite & $25 \%$ & $34 \%$ & $1 \%$ & $2 \%$ & $29 \%$ & $8 \%$ & $2 \%$ \\
\hline Calcined laterite & $27 \%$ & - & $3 \%$ & - & - & $70 \%$ & - \\
\hline Geopolymer & $38 \%$ & - & $2 \%$ & - & - & $60 \%$ & - \\
\hline
\end{tabular}

Table 3

Phase composition from EDX of geopolymer without fibers.

\begin{tabular}{|c|c|c|c|c|c|c|c|c|c|}
\hline \multicolumn{5}{|c|}{ Concentration of elements (wt\%) } & \multicolumn{4}{|c|}{ Molar ratio } & \multirow[t]{2}{*}{ Phases } \\
\hline $\mathrm{O}$ & $\mathrm{Na}$ & $\mathrm{Al}$ & $\mathrm{Si}$ & $\mathrm{Fe}$ & $\mathrm{Si} / \mathrm{Al}$ & $\mathrm{Si} / \mathrm{Fe}$ & $\mathrm{Na} / \mathrm{Al}$ & $\mathrm{Na} / \mathrm{Fe}$ & \\
\hline 30.62 & 3.85 & 5.08 & 3.99 & 56.46 & 0.76 & 0.14 & 0.89 & 0.17 & Unreacted hematite embedded with geopolymer binder \\
\hline 21.96 & 4.12 & 7.67 & 4.87 & 61.39 & 0.61 & 0.16 & 0.63 & 0.16 & \\
\hline 41.80 & 1.93 & 34.38 & 19.87 & 2.02 & 0.56 & 19.67 & 0.07 & 2.33 & Unreacted particles \\
\hline 40.99 & 11.48 & 13.78 & 23.20 & 10.04 & 1.62 & 4.62 & 0.98 & 2.78 & Geopolymer binder \\
\hline 42.64 & 12.03 & 12.69 & 20.45 & 11.9 & 1.55 & 3.45 & 1.11 & 2.46 & Geopolymer binder \\
\hline 29.70 & 2.95 & 8.94 & 7.10 & 51.32 & 0.77 & 0.28 & 0.39 & 0.14 & Unreacted hematite embedded with geopolymer binder \\
\hline 25.81 & 4.15 & 6.47 & 5.07 & 57.98 & 0.76 & 0.17 & 0.75 & 0.17 & \\
\hline 38.79 & 3.85 & 34.54 & 21.41 & 1.41 & 0.60 & 30.37 & 0.13 & 6.68 & Unreacted particles \\
\hline 39.81 & 10.78 & 15.21 & 25.24 & 8.97 & 1.60 & 5.63 & 0.83 & 2.93 & Geopolymer binder \\
\hline 40.13 & 11.70 & 14.63 & 24.75 & 8.15 & 1.63 & 6.07 & 0.93 & 3.49 & Geopolymer binder \\
\hline 51.51 & - & - & 48.49 & - & - & - & - & - & Unreacted Quartz \\
\hline 52.52 & - & - & 47.48 & - & - & - & - & - & Unreacted Quartz \\
\hline 51.13 & 6.19 & 5.86 & 27.53 & 8.25 & 4.53 & 6.67 & 1.24 & 1.83 & Si-rich geopolymer binder \\
\hline 46.52 & - & - & 53.48 & - & - & - & - & - & Unreacted Quartz \\
\hline 51.00 & 7.49 & 7.94 & 23.79 & 9.28 & 2.89 & 5.12 & 1.11 & 1.96 & Geopolymer binder \\
\hline
\end{tabular}

molar ratios $\mathrm{Si} / \mathrm{Al}=4.53, \mathrm{Si} / \mathrm{Fe}=6.67, \mathrm{Na} / \mathrm{Al}=1.24, \mathrm{Na} / \mathrm{Fe}=1.83$ and corresponds to a Si-rich geopolymer binder of polyferrosialate-multisiloxo type (Djobo et al., 2016a; Kaze et al., 2018a, 2018b). The good balance of the $\mathrm{Na}^{+}$ion in the matrix characterized by the low value of molar ratio $\mathrm{Na} / \mathrm{Al}$ denotes that there is only a few free $\mathrm{Na}^{+}$ions in the system and corroborates the FTIR result (Fig. 3) where the vibration band characteristic of efflorescence was very low.

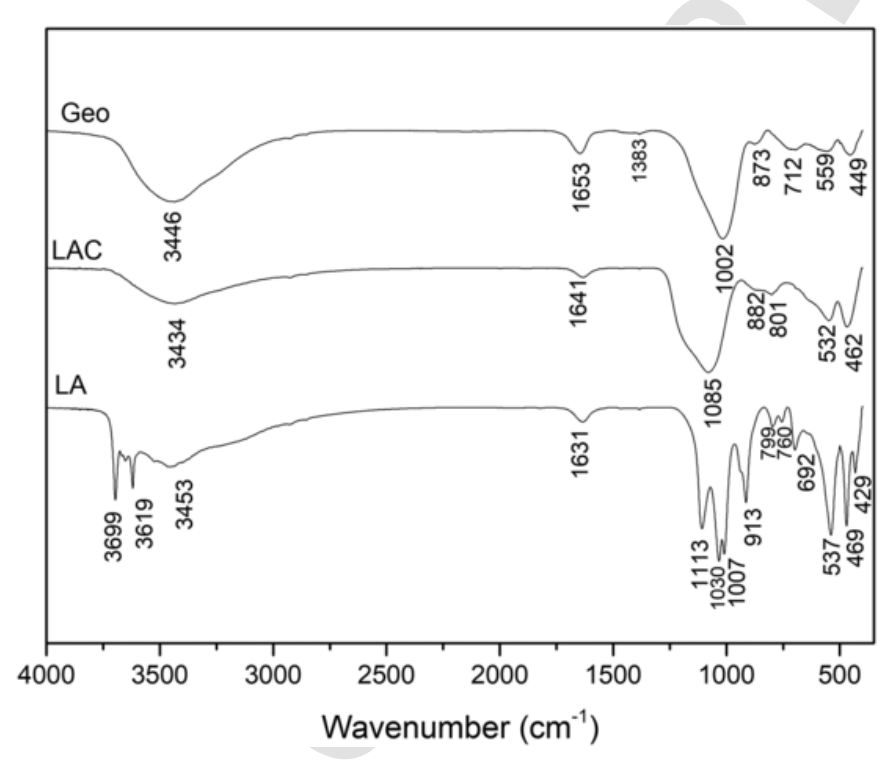

Fig. 3. Infrared spectra of raw (LA), calcined laterite (LAC) and neat Geopolymer (Geo).

\subsection{Mechanical properties of geopolymer composite}

\subsubsection{Compressive stress-strain behavior}

Fig. 5 shows the ultimate compressive stress evolution and the failure mode of geopolymer composite under compression. The ultimate compressive stress (Fig. 5a) decreases with fiber content from 50 MPa for the reference geopolymer (without fibers) to $14 \mathrm{MPa}$ for geopolymer composite with $7.5 \mathrm{wt} \%$ of fibers. It is worth pointing out that the strength development in composite materials is generally due to the aptitude of fibers to withstand to the load and to the fibers-matrix interface (Silva et al., 2009; Assaedi et al., 2015). That sharp decrease of stress of natural fibers based composite materials can be due to factors like the low adhesion of the fibers to the geopolymer matrix or the low resistance of the fibers to the load. It must be recalled that the sugarcane fibers used in this work come from sugar production factory. This means that it has passed through processes of millings (crushing, cutting and shredding) for the extraction of juice from the cane stalk under higher pressure (Loh et al., 2013). This process partially degrades the physical characteristics of the sugarcane fibers and make the sugarcane fibers-reinforced composite to develop inferior strength compared to other natural fibers (Luz et al., 2008; Loh et al., 2013; Hossain et al., 2014). Therefore, instead of making a bridge to retard cracks propagation within the composite, the fiber breaks itself under compression load, creating weak points in the specimens. This accelerates the cracks propagation leading to an early failure of the geopolymer composite: thus, the higher sugarcane fibers content, the higher cracks propagation rate. Later the contribution of the fiber-matrix interface adhesion to the strength decrease will be discussed to show up the failure mechanism. The fibers orientation might be also responsible for strength decrease. Since the fibers were randomly oriented in the matrix this could contribute to the low-stress transfer throughout the matrix, resulting in strength diminishing (Alomayri et al., 2014b). 

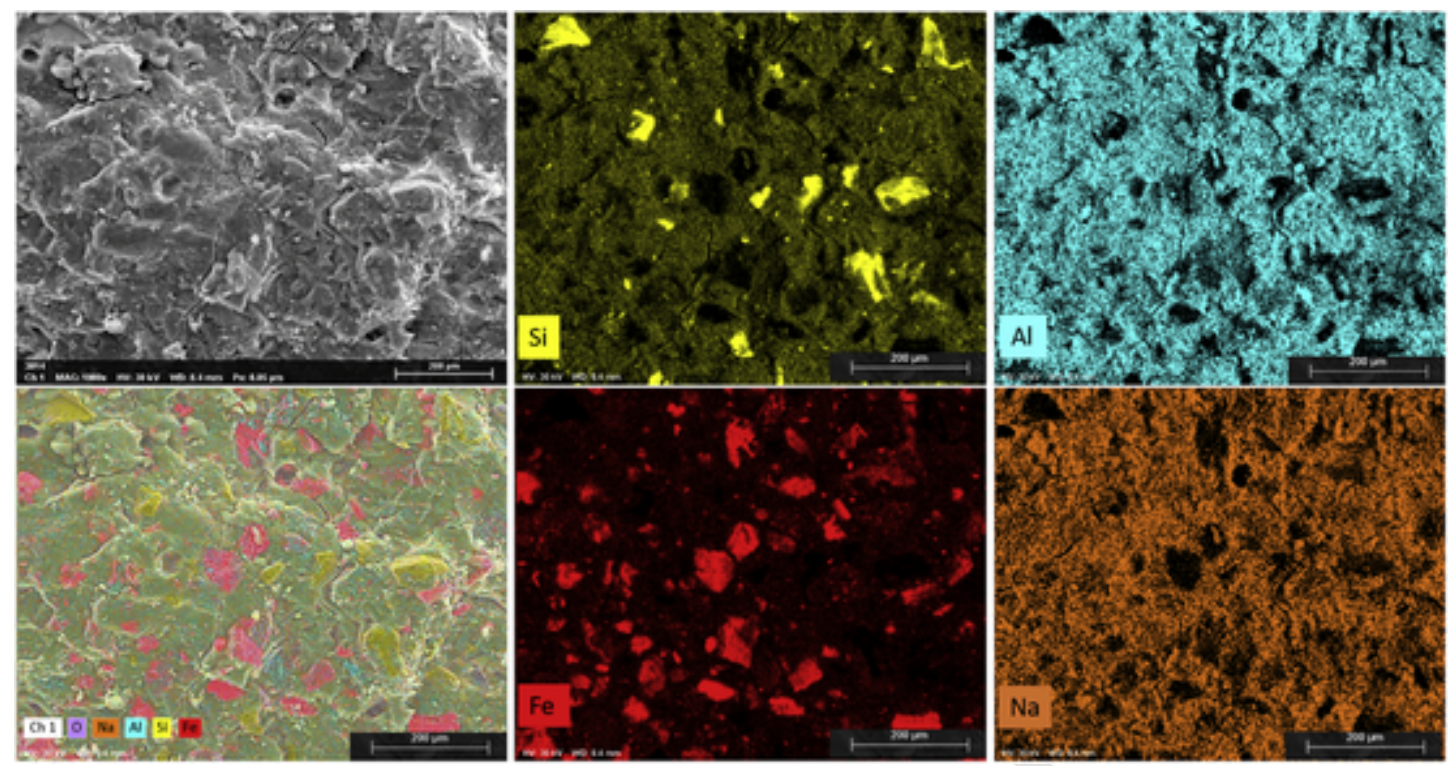

Fig. 4. Micrograph and elemental map of neat geopolymer without fibers.
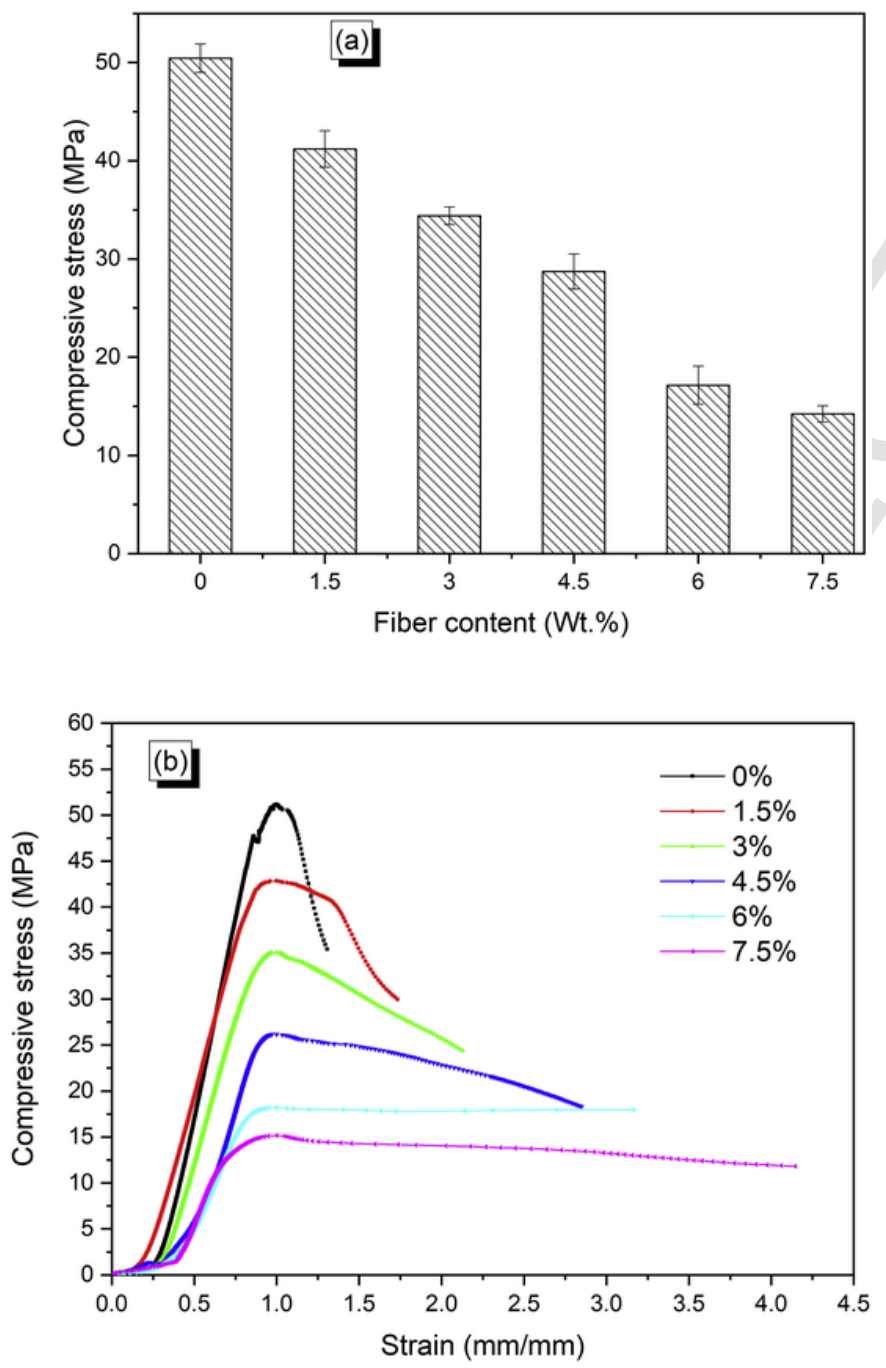

Fig. 5. (a) Ultimate compressive stress and (b) compressive stress-strain behavior of geopolymer composites.
The geopolymer without fibers exhibits a brittle failure, while the response of the geopolymer composite under compressive stress shows a highly ductile strain which is improved with the fibers content (Fig. $5 b)$. The latter can be ascertained by the increase of the strain with the gradual decrease of the load, translating a typical pseudo elastic behaviour (Li et al., 2018).

\subsubsection{Flexural stress-strain curves and modulus of elasticity}

Under flexural stress the reference geopolymer (without fibers) displays a disastrous failure; on the contrary, geopolymer composite presents a ductile behaviour (Fig. 6a). There is no clear trend of the ultimate flexural stress with fibers content (Fig. 6b), probably due to the random orientation of the fibers. It was indeed reported that when the fibers have a specific orientation (horizontal or vertical) they can easily absorb and uniformly distribute the load throughout the matrix (Alomayri et al., 2014b). To understand the effect of fibers content on failure mode under flexural stress, the modulus of elasticity was calculated by the tangent method and reported in Fig. 7. The modulus of elasticity increases from 4.39 to $6.50 \mathrm{GPa}$ with up to $3 \mathrm{wt} \%$ of fibers contents, then it further decreases to $2.34 \mathrm{GPa}$ with fibers content. It can be observed that the addition of $3 \mathrm{wt} \%$ of fibers increases the modulus of elasticity of up to $43 \%$. That increase might be due to the fibers which absorb load and delay the failure of the specimen. But this effect is limited by the content of fibers to $3 \mathrm{wt} \%$.

\subsubsection{The failure mechanism of geopolymer composite}

The failure mechanism of geopolymer composite as observed by Scanning Electron Microscopy (Fig. 8) include the matrix fibers pull-out (B), the fiber debonding (C) and obviously the matrix breakage. The fact that the fibers have a random orientation in the matrix can favor these two types of failure mechanisms to the breakage of the fibers as the load is not always perpendicular to the fibers to trigger its rupture (Alomayri et al., 2014b; Assaedi et al., 2015). The fibers debonding is the proof of the weak fibers-matrix adhesion, this agrees with the small crack or void observed in the fibers-matrix interface (micrograph D). 

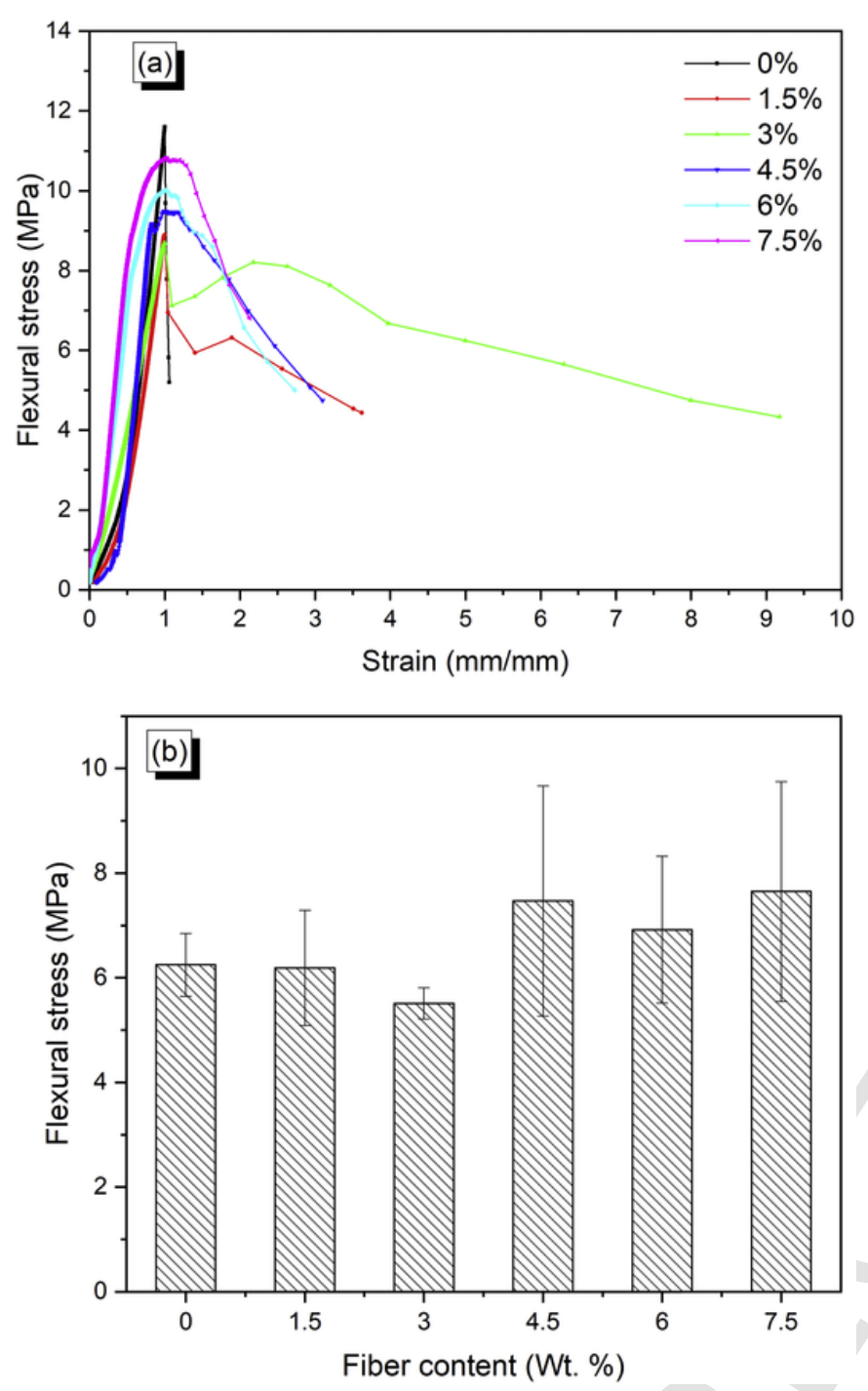

Fig. 6. (a) Flexural stress-strain curves and (b) ultimate flexural stress of geopolymer composites.

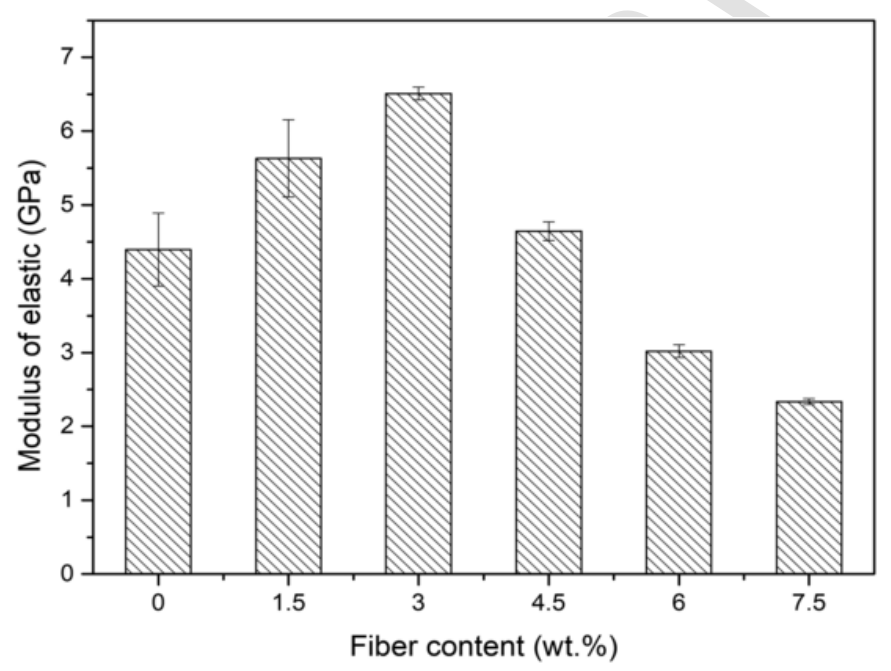

Fig. 7. Modulus of elasticity of geopolymer and fiber reinforced geopolymer composites (FRGP).

\subsection{Durability characteristics}

\subsubsection{Water absorption behavior}

Fig. 9 shows the water absorption behaviour by capillary suction over time. Table 4 reports the capillary water absorption coefficient determined as the initial slope of the sorptivity curves up to the beginning of saturation and the final values of the maximum water absorbed For all specimens, the water absorption rate increases rapidly at an early time to reach a saturation where the increase becomes very slow. This trend follows the typical Fickian diffusion behavior as it is common for fibers-polymer composite (Alomayri et al., 2014a). For the geopolymer composite, the water penetration rate is lowest from early to late time compared to reference geopolymer. But there is no a clear trend of the water absorption coefficient versus the fibers content, although the fibers delay the rate of water penetration, the final water uptake of the geopolymer composite remains $18 \%$ higher than the one of reference geopolymer. This may be due firstly to the fact that when water reaches the fibers it is adsorbed for developing hydrogen bonds, which hinders it further diffusion throughout capillary pores within the matrix (Venkateshwaran et al., 2011; Alomayri et al., 2014a). Finally, that water absorbed is no longer released by the fibers and it allows the fibers swelling. (Dhakal et al., 2007).

\subsection{Resistance to wet-dry cycles.}

The effect of wet-dry cycles on the fracture behavior and compressive strength are depicted in Figs. 10 and 11 respectively. The ultimate compressive strength after exposure of the geopolymer composite to 20 wet and dry cycles does not significantly change the results (Fig. 11). It means that the geopolymer sample remains stable and the fibers are not degraded as reported in previous works (Puertas et al., 2003). However, the failure mode after 20 wet-dry cycles (Fig. 10) shows an improved of the brittleness of the reference geopolymer (Fig. 10a) whereas the ductile failure of the composite seems to be improved (Fig. 10b). The latter is due to the improvement of the fiber-geopolymer matrix adhesion because of the modification of the chemical composition of the fibers during the accelerated aging under hot and wet condition that enhances the adhesion of the fibers to the geopolymer matrix (Trindade et al., 2018).

\subsection{Thermal insulating properties}

The results of the thermal conductivity $(\lambda, \mathrm{W} / \mathrm{mK})$ at different age of geopolymer composite are shown in Fig. 12. The thermal conductivity decreases with the age of samples and the percentage of fibers added. At 28 days the thermal conductivity decreases from $0.77 \mathrm{~W} / \mathrm{mK}$ for the reference geopolymer to $0.55 \mathrm{~W} / \mathrm{mK}$ for the geopolymer composite with $7.5 \mathrm{wt} \%$ of fibers. The low thermal conductivity is generally related to the presence of pores or void inside the matrix which, slow down the rate of heat transfer because of the very low thermal conductivity of the air $(0.0262 \mathrm{~W} / \mathrm{mK})$ contained in these pores. Thus, the diminishing on thermal conductivity with the age of samples translates the increase of porosity. The latter is likely due to the evaporation of the free water initially contained in the pores at an early age and which has high thermal conductivity compared to air $(0.6 \mathrm{~W} / \mathrm{mK})$. In the case of geopolymer composite, the low thermal conductivity induced by the presence of fibers is likely due to their low thermal conductivity $0.08 \mathrm{~W} / \mathrm{mK}$ and to the presence of additional voids at the interface fibers-matrix. The value of thermal conductivity of the geopolymer composite make them suitable to be used as insulating materials (Tajra et al., 2019). 

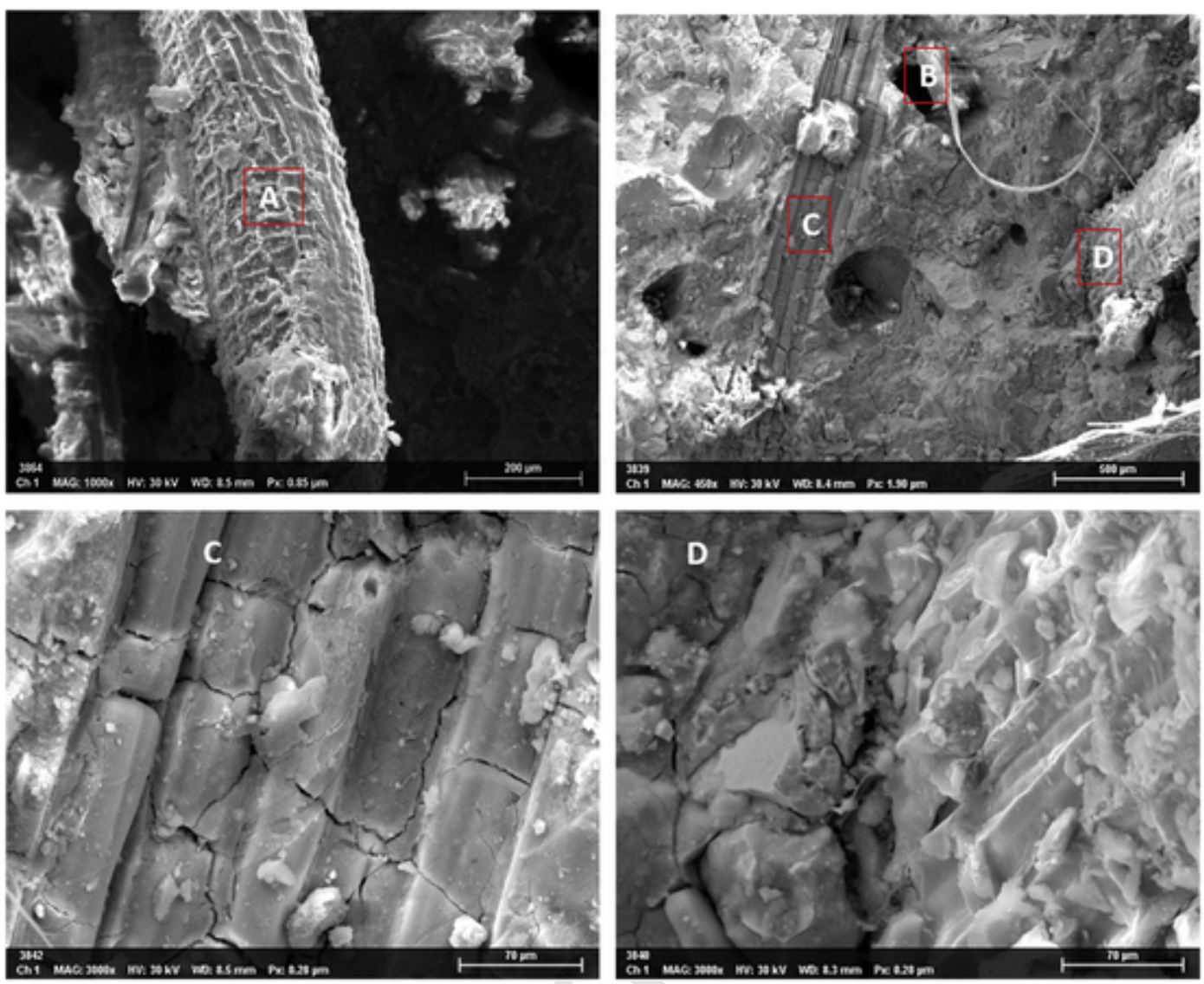

Fig. 8. Micrographs of the fibers (A) and geopolymer composite showing the various failure mechanism and: $B=$ fiber pull-out; $C=$ fiber de-bonding; $D=$ fiber-matrix adhesion.

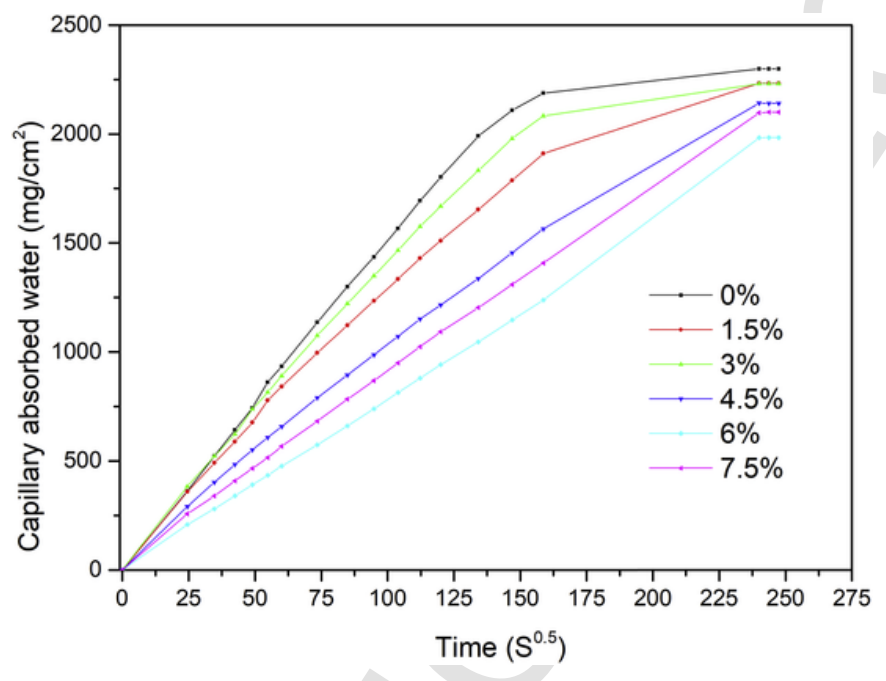

Fig. 9. Capillary water absorption test.

\section{Conclusion}

This work has reported the potential of sugar cane bagasse as reinforcement into iron-rich laterite-based geopolymer cement. The effect of this natural fibers on the fracture behavior has been studied and the durability characteristics investigated. The main conclusions are the followings:

- The sugar cane bagasse fibers have successfully turned the brittle failure mode of geopolymer into pseudo-elastic failure mode characteristic of ductile behavior;

- The different failure mechanism includes the matrix and fibers breakage, fibers pull-out and debonding;

- The fiber breakage and fiber-matrix interface are the main mechanisms responsible for strength decrease of the geopolymer composite;

- The fibers slow-down the rate of water penetration rate in the geopolymer composite, however because of their hydrophilic character the final water absorption is still higher;

- Under accelerated wet-dry cycles, geopolymer with fibers performed well, but the reference geopolymer becomes more brittle whereas the ductility of the composite keeps enhancing.

- The fibers were beneficial for reducing the thermal conductivity of the geopolymer composite, which makes them suitable for the thermal insulating application.

\section{Acknowledgment}

The authors would like to thank the Académie de Recherche et d'Enseignement Supérieur of the Government of Wallonia-Brussels Federation for financial support through the internship SeRaMa "Valorisation des Ressources Secondaires pour une Construction Durable" (2017). 

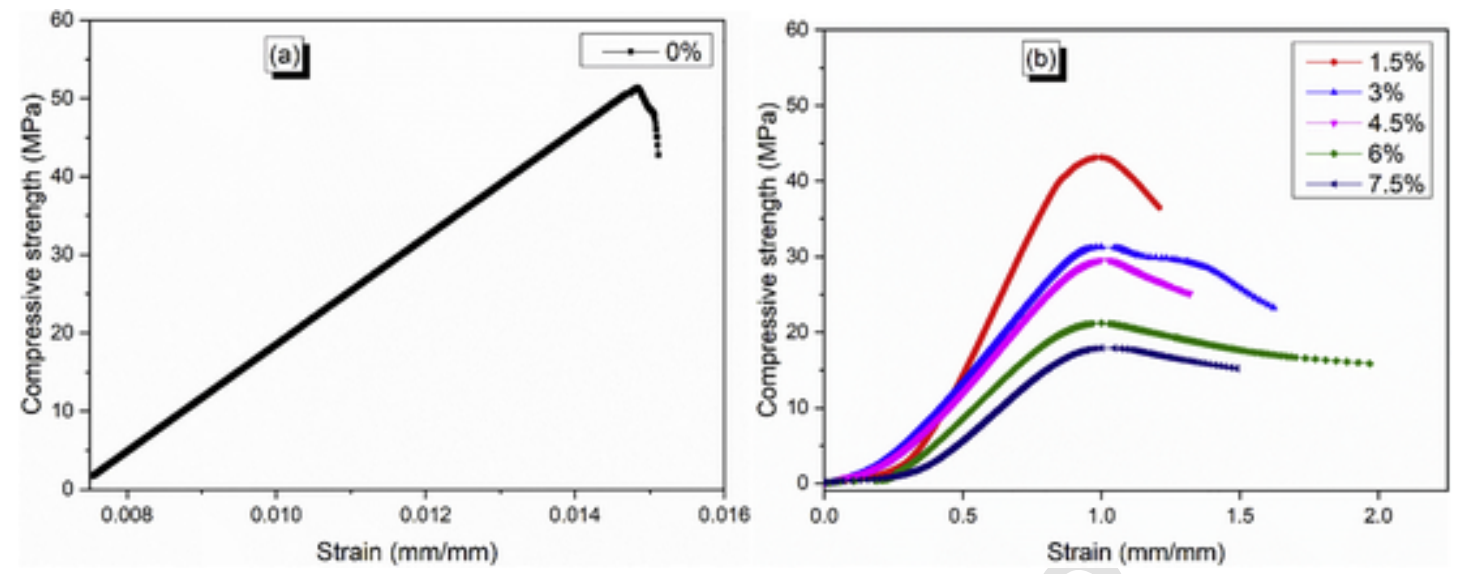

Fig. 10. Fracture behaviour under compression after 20 wet-dry cycles: (a) reference geopolymer, (b) geopolymer composite.

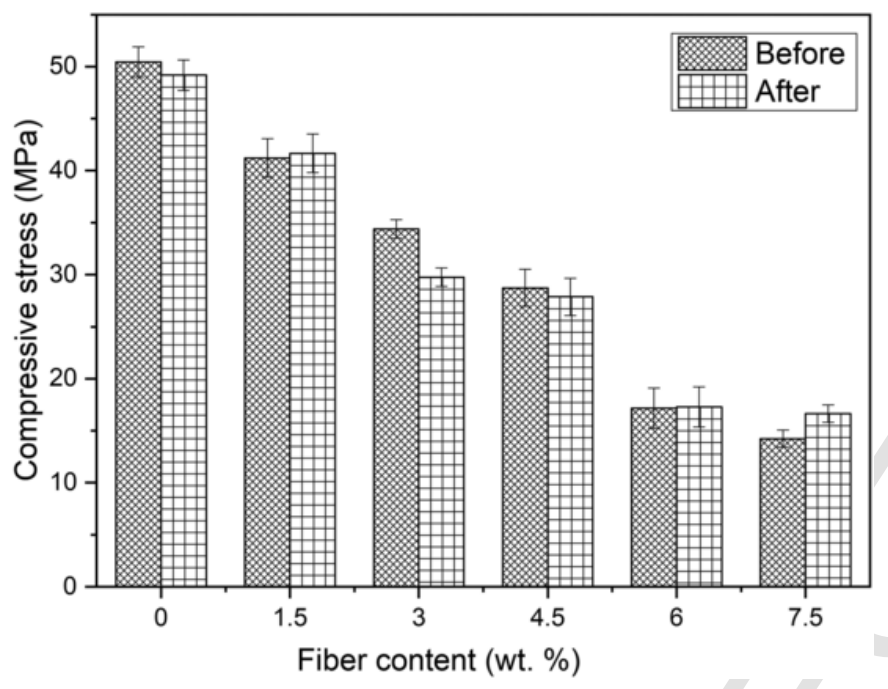

Fig. 11. Compressive stress evolution before and after 20 wet and dry cycles.

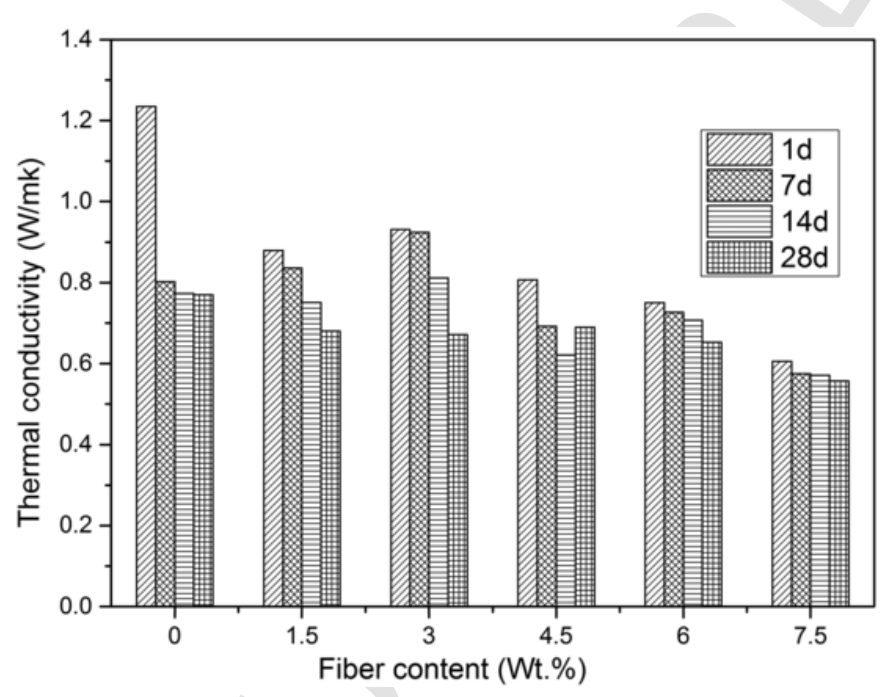

Fig. 12. Thermal conductivity of geopolymer composite at various age. 
Table 4

Capillary water absorption coefficient $(\mathrm{k})$ and total water absorbed.

\begin{tabular}{|c|c|c|c|c|c|c|}
\hline Fiber content (\%) & 0 & 1.5 & 3 & 4.5 & 6 & 7.5 \\
\hline $\mathrm{K}\left(\mathrm{mg} / \mathrm{cm}^{2} \mathrm{~s}^{0.5}\right)$ & 14.25 & 9.96 & 13.14 & 8.51 & 8.10 & 8.47 \\
\hline Correlation coefficient, $r$ & 0.99457 & 0.949 & 0.99637 & 0.99031 & 0.99864 & 0.99887 \\
\hline Total water absorption (\%) & 19.90 & 19.90 & 22.00 & 21.08 & 21.66 & 24.26 \\
\hline
\end{tabular}

\section{References}

Alomayri, T., Shaikh, F.U.A., Low, I.M., 2013. Characterisation of cotton fibre-reinforced geopolymer composites. Compos. Part B Eng. 50, 1-6. doi:10.1016/ j.compositesb.2013.01.013.

Alomayri, T., Assaedi, H., Shaikh, F.U.A., Low, I.M.M., 2014. Effect of water absorption on the mechanical properties of cotton fabric-reinforced geopolymer composites. J. Asian Ceram. Soc. 2, 223-230. doi:10.1016/j.jascer.2014.05.005.

Alomayri, T., Shaikh, F.U.A., Low, I.M., 2014. Effect of fabric orientation on mechanical properties of cotton fabric reinforced geopolymer composites. Mater. Des. 57, 360-365. doi:10.1016/j.matdes.2014.01.036.

Alshaaer, M., Mallouh, S.A., Al-Kafawein, J., Al-Faiyz, Y., Fahmy, T., Kallel, A., Rocha, F., 2017. Fabrication, microstructural and mechanical characterization of Luffa Cylindrical Fibre - Reinforced geopolymer composite. Appl. Clay Sci. 143, 125-133. doi:10.1016/j.clay.2017.03.030.

Assaedi, H., Alomayri, T., Shaikh, F.U.A., Low, I.M., 2015. Characterisation of mechanical and thermal properties in flax fabric reinforced geopolymer composites. J. Adv. Ceram. 4, 272-281. doi:10.1007/s40145-015-0161-1.

Assaedi, H., Alomayri, T., Shaikh, F.U.A., Low, I.M., 2018. Advances in geopolymer composites with natural reinforcement, in. Second Edition. Elsevier Ltd, Advances in Ceramic Matrix Composites, pp. 461-474. doi:10.1016/B978-0-08-102166-8.00019-0.

Bhutta, A., Borges, P.H.R., Zanotti, C., Farooq, M., Banthia, N., 2017. Flexural behavior of geopolymer composites reinforced with steel and polypropylene macro fibers. Cem. Concr. Compos. 80, 31-40. doi:10.1016/j.cemconcomp.2016.11.014.

Dhakal, H.N., Zhang, Z.Y., Richardson, M.O.W., 2007. Effect of water absorption on the mechanical properties of hemp fibre reinforced unsaturated polyester composites. Compos. Sci. Technol. 67, 1674-1683. doi:10.1016/j.compscitech.2006.06.019.

Djobo, J.N.Y., Elimbi, A., Tchakouté, H.K., Kumar, S., 2016. Reactivity of volcanic ash in alkaline medium, microstructural and strength characteristics of resulting geopolymers under different synthesis conditions. J. Mater. Sci. 51, 10301-10317. doi:10.1007/s10853-016-0257-1.

Djobo, J.N.Y., Elimbi, A., Tchakouté, H.K., Kumar, S., 2016. Mechanical properties and durability of volcanic ash based geopolymer mortars. Constr. Build. Mater. 124, 606-614. doi:10.1016/j.conbuildmat.2016.07.141.

Gouny, F., Fouchal, F., Maillard, P., Rossignol, S., 2014. Study of the effect of siliceous species in the formation of a geopolymer binder: understanding the reaction mechanisms among the binder, wood, and earth brick. Ind. Eng. Chem. Res. 53, 3559-3569. doi:10.1021/ie403670c.

Hossain, M.K., Karim, M.R., Chowdhury, M.R., Imam, M.A., Hosur, M., Jeelani, S., Farag, R., 2014. Comparative mechanical and thermal study of chemically treated and untreated single sugarcane fiber bundle. Ind. Crop. Prod. 58, 78-90. doi:10.1016/ j.indcrop.2014.04.002.

Kaze, R.C., Beleuk à Moungam, L.M., Fonkwe Djouka, M.L., Nana, A., Kamseu, E., Chinje Melo, U.F., Leonelli, C., 2017. The corrosion of kaolinite by iron minerals and the effects on geopolymerization. Appl. Clay Sci. 138, 48-62. doi:10.1016/ j.clay.2016.12.040.

Kaze, R.C., Beleuk à Moungam, L.M., Cannio, M., Rosa, R., Kamseu, E., Melo, U.C., Leonelli, C., 2018. Microstructure and engineering properties of Fe2O3(FeO)-Al2O3-SiO2based geopolymer composites. J. Clean. Prod. 199, 849-859. doi:10.1016/j.jclepro.2018.07.171.

Kaze, R.C., Djobo, J.N.Y., Nana, A., Tchakoute, H.K., Kamseu, E., Melo, U.C., Leonelli, C., Rahier, H., 2018. Effect of silicate modulus on the setting, mechanical strength and microstructure of iron-rich aluminosilicate (laterite) based-geopolymer cured at room temperature. Ceram. Int. 44, 21442-21450. doi:10.1016/j.ceramint.2018.08.205.

Lassinantti Gualtieri, M., Romagnoli, M., Pollastri, S., Gualtieri, A.F., 2015. Inorganic polymers from laterite using activation with phosphoric acid and alkaline sodium silicate solution: mechanical and microstructural properties. Cem. Concr. Res. 67, 259-270. doi:10.1016/j.cemconres.2014.08.010.

Lemougna, P.N., MacKenzie, K.J.D., Jameson, G.N.L., Rahier, H., Chinje Melo, U.F., 2013. The role of iron in the formation of inorganic polymers (geopolymers) from volcanic ash: a 57Fe M??ssbauer spectroscopy study. J. Mater. Sci. 48, 5280-5286. doi:10.1007/s10853-013-7319-4.

Lemougna, P.N., Balo, A.M., Kamseu, E., Chinje Melo, U., Delplancke, M.-P., Rahier, H., 2014. Influence of the processing temperature on the compressive strength. Constr. Build. Mater. 65, 60-66.

Li, Y., Li, W., Deng, D., Wang, K., Duan, W.H., 2018. Reinforcement effects of polyvinyl alcohol and polypropylene fibers on flexural behaviors of sulfoaluminate cement matrices. Cem. Concr. Compos. 88, 139-149. doi:10.1016/j.cemconcomp.2018.02.004.

Loh, Y.R., Sujan, D., Rahman, M.E., Das, C.A., 2013. Review Sugarcane bagasse - The future composite material: a literature review. Resour. Conserv. Recycl. 75, 14-22. doi:10.1016/j.resconrec.2013.03.002.

Luz, S.M., Del Tio, J., Rocha, G.J.M., Gonçalves, A.R., Del'Arco, A.P., 2008. Cellulose and cellulignin from sugarcane bagasse reinforced polypropylene composites: Effect of acetylation on mechanical and thermal properties. Compos. Part A Appl. Sci. Manuf. 39, 1362-1369. doi:10.1016/j.compositesa.2008.04.014.

Mohr, B.J., Nanko, H., Kurtis, K.E., 2005. Durability of kraft pulp fiber-cement composites to wet/dry cycling. Cem. Concr. Compos. 27, 435-448. doi:10.1016/ j.cemconcomp.2004.07.006.

Najafi Kani, E., Allahverdi, A., Provis, J.L., 2012. Efflorescence control in geopolymer binders based on natural pozzolan. Cem. Concr. Compos. 34, 25-33. doi:10.1016/ j.cemconcomp.2011.07.007.

Obonyo, E.A., Kamseu, E., Lemougna, P.N., Tchamba, A.B., Melo, U.C., Leonelli, C., 2014. A Sustainable Approach for the Geopolymerization of Natural Iron-rich Aluminosilicate Materials. pp. 5535-5553. doi:10.3390/su6095535.

Oyelami, C.A., Van Rooy, J.L., 2016. A review of the use of lateritic soils in the construction/development of sustainable housing in Africa: a geological perspective. J. Afr. Earth Sci. 119, 226-237. doi:10.1016/j.jafrearsci.2016.03.018.

Puertas, F., Amat, T., Fernández-Jiménez, A., Vázquez, T., 2003. Mechanical and durable behaviour of alkaline cement mortars reinforced with polypropylene fibres. Cem. Concr. Res. 33, 2031-2036. doi:10.1016/S0008-8846(03)00222-9.

Sellami, M., Barre, M., Toumi, M., 2019. Synthesis, thermal properties and electrical conductivity of phosphoric acid-based geopolymer with metakaolin. Appl. Clay Sci. 180, 105192. doi:10.1016/j.clay.2019.105192.

Shaikh, F.U.A., 2013. Review of mechanical properties of short fibre reinforced geopolymer composites. Constr. Build. Mater. 43, 37-49. doi:10.1016/ j.conbuildmat.2013.01.026.

Sikora, P., Abd, M., Chung, S., Cendrowski, K., 2019. Mechanical and microstructural properties of cement pastes containing carbon nanotubes and carbon nanotube-silica core-shell structures, exposed to elevated temperature. Cem. Concr. Compos. 95, 193-204. doi:10.1016/j.cemconcomp.2018.11.006.

Silva, F. de A., Mobasher, B., Filho, R.D.T., 2009. Cracking mechanisms in durable sisal fiber reinforced cement composites. Cem. Concr. Compos. 31, 721-730. doi:10.1016/ j.cemconcomp.2009.07.004.

Tajra, F., Elrahman, M.A., Stephan, D., 2019. The production and properties of cold-bonded aggregate and its applications in concrete: a review. Constr. Build. Mater. 225, 29-43. doi:10.1016/j.conbuildmat.2019.07.219.

Trindade, A.C.C., Silva, F.A., Alcamand, H.A., Borges, P.H.R., 2018. On the durability behavior of natural fiber reinforced geopolymers. In: Proceedings of the 41st International Conference on Advanced Ceramics and Composites: Ceram. Eng. Sci. Proc. pp. 215-228. doi:10.1002/9781119474746.ch20.

Venkateshwaran, N., ElayaPerumal, A., Alavudeen, A., Thiruchitrambalam, M., 2011. Mechanical and water absorption behaviour of banana/sisal reinforced hybrid composites. Mater. Des. 32, 4017-4021. doi:10.1016/j.matdes.2011.03.002.

Yan, L., Kasal, B., Huang, L., 2016. A review of recent research on the use of cellulosic fibres, their fibre fabric reinforced cementitious, geo-polymer and polymer 
composites in civil engineering. Compos. Part B Eng. 92, 94-132. doi:10.1016/ j.compositesb.2016.02.002.

Ye, H., Zhang, Y., Yu, Z., Mu, J., 2018. Effects of cellulose, hemicellulose, and lignin on the morphology and mechanical properties of metakaolin-based geopolymer. Constr. Build. Mater. 173, 10-16. doi:10.1016/j.conbuildmat.2018.04.028.
Zuhua, Z., Xiao, Y., Huajun, Z., Yue, C., 2009. Role of water in the synthesis of calcined kaolin-based geopolymer. Appl. Clay Sci. 43, 218-223. doi:10.1016/ j.clay.2008.09.003. 